\title{
Experimental validation of a methodology to control irrigation canals based on Saint-Venant equations
}

\author{
Xavier Litrico $^{\mathrm{a}, *}$, Vincent Fromion ${ }^{\mathrm{b}}$, Jean-Pierre Baume ${ }^{\mathrm{a}}$, Carina Arranja ${ }^{\mathrm{c}}$, Manuel Rijo \\ ${ }^{a}$ Unité de Recherche Irrigation, Cemagref, B.P. 5095, 34033 Montpellier Cedex 1, France \\ ${ }^{\mathrm{b}}$ Laboratoire d'Analyse des Systèmes et Biométrie, INRA, 2 place Viala, 34060 Montpellier, France \\ ${ }^{\mathrm{c}}$ Universidade de Évora, Departamento de Engenharia Rural, Colégio da Mitra, Apartado 94, 7002-554 Évora, Portugal
}

Received 19 April 2004; accepted 22 December 2004

Available online 3 February 2005

\section{Abstract}

This paper exposes and validates a methodology based on a classical hydraulic model (Saint-Venant equations) to design efficient automatic controllers for an irrigation canal pool. The method is applied on a laboratory canal located in Portugal. First, the full nonlinear hydraulic model is calibrated, using a single steady-state experiment, then it is validated on other hydraulic conditions. The control model is obtained by linearizing the Saint-Venant equations and using a numerical method to compute the frequency response of the system. Simple controllers are designed and analyzed using the linearized models. The experimental results show that such a method is able to accurately predict the closed-loop system behavior in terms of stability, robustness and performance. (C) 2005 Elsevier Ltd. All rights reserved. 